\title{
Sex differences in uterine artery Doppler during gestation in pregnancies complicated by placental dysfunction
}

Leah Paranavitana', Melissa Walker ${ }^{2,3}$, Anjana Ravi Chandran², Natasha Milligan ${ }^{4}$, Shiri Shinar ${ }^{2}$, Clare L. Whitehead ${ }^{5}$, Sebastian R. Hobson², Lena Serghides ${ }^{6,7,8}$, W. Tony Parks ${ }^{9,10}$, Ahmet A. Baschat ${ }^{11}$, Christopher K. Macgowan ${ }^{12,13}$, John G. Sled ${ }^{3,12,13,14}$, John C. Kingdom ${ }^{2,3}$ and Lindsay S. Cahill ${ }^{1 *}$ (D)

\begin{abstract}
Background: There is growing evidence of sex differences in placental vascular development. The objective of this study was to investigate the effect of fetal sex on uterine artery pulsatility index (PI) throughout gestation in a cohort of normal and complicated pregnancies.

Methods: A prospective longitudinal study was conducted in 240 pregnant women. Pulsed wave Doppler ultrasound of the proximal uterine arteries was performed at a 4-weekly interval between 14 and 40 weeks of gestation. The patients were classified retrospectively as normal or complicated (one or more of maternal preeclampsia, preterm birth, or small for gestational age). To assess if the change in uterine artery PI during gestation differed between normal and complicated pregnancies and between fetal sexes, the uterine artery PI was modeled using a linear function of gestational age and the rate of change was estimated from the slope.

Results: While the uterine artery PI did not differ over gestation between females and males for normal pregnancies, the trajectory of this index differed by fetal sex for pregnancies complicated by either preeclampsia, preterm birth, or fetal growth restriction $(p<0.0001)$. The male fetuses in the complicated pregnancy group had an elevated slope compared to the other groups $(p<0.0001)$, suggesting a more progressive deterioration in uteroplacental perfusion over gestation.

Conclusions: The uterine artery PI is widely used to assess uteroplacental function in clinical settings. The observation that this metric changes more rapidly in complicated pregnancies where the fetus was male highlights the importance of sex when interpreting hemodynamic markers of placental maturation.
\end{abstract}

Keywords: Doppler ultrasound, Fetal sex, Pregnancy, Pulsatility index, Sex differences, Uterine artery

\footnotetext{
* Correspondence: Icahill@mun.ca

'Department of Chemistry, Memorial University of Newfoundland, 283 Prince Philip Drive, St John's, Newfoundland and Labrador A1B 3X7, Canada

Full list of author information is available at the end of the article
}

C C The Author(s). 2021 Open Access This article is licensed under a Creative Commons Attribution 4.0 International License, which permits use, sharing, adaptation, distribution and reproduction in any medium or format, as long as you give appropriate credit to the original author(s) and the source, provide a link to the Creative Commons licence, and indicate if changes were made. The images or other third party material in this article are included in the article's Creative Commons licence, unless indicated otherwise in a credit line to the material. If material is not included in the article's Creative Commons licence and your intended use is not permitted by statutory regulation or exceeds the permitted use, you will need to obtain permission directly from the copyright holder. To view a copy of this licence, visit http://creativecommons.org/licenses/by/4.0/. The Creative Commons Public Domain Dedication waiver (http://creativecommons.org/publicdomain/zero/1.0/) applies to the data made available in this article, unless otherwise stated in a credit line to the data. 


\section{Background}

Metabolic demand increases exponentially as gestation progresses, thereby requiring that the uteroplacental circulation adapt to deliver increased blood flow. Insufficient uterine vascular remodeling is associated with preeclampsia, preterm birth, and fetal growth restriction [1-3]. Clinically, changes in uteroplacental blood flow are measured by uterine artery Doppler waveforms and described by the pulsatility index (PI). In healthy pregnancies, the uterine artery PI decreases over gestation [4, 5]. An increased uterine artery PI, with or without an early diastolic notch, is an indicator of uteroplacental vascular insufficiency, and has been demonstrated in cross-sectional studies to be associated with poor perinatal outcomes [6-9].

Sex-specific differences in pregnancy outcomes are well-established. For example, male fetuses are at an increased risk of fetal distress, preterm birth, or early neonatal death [10-14] while female fetuses have a greater risk of mortality during gestation [15]. There is a higher incidence of early onset preeclampsia in women carrying female fetuses [16-18]. Sex differences have also been reported for both placental structure and function [1924]. Placental pathology has been shown to be dependent on fetal sex, with males exhibiting inflammatory pathology and females having a greater risk for placental infarction [25]. Recent studies have found sex differences in umbilical artery PI over the second half of gestation in uncomplicated pregnancies $[26,27]$. In the present study, we investigated the effect of fetal sex on uterine artery PI throughout gestation in a cohort of normal and complicated pregnancies.

\section{Methods}

\section{Patient cohort}

Uterine artery measurements were acquired prospectively as part of a study that evaluated a new methodology for measuring umbilical artery hemodynamics. The latter study, which will be reported elsewhere, dictated the study sample size and inclusion criteria. A longitudinal ultrasound study was conducted in 240 women recruited in the first trimester of pregnancy. Inclusion criteria were maternal age between 18 and 45 years, body mass index $(\mathrm{BMI})<45 \mathrm{~kg} / \mathrm{m}^{2}$, singleton pregnancy, and no significant maternal comorbidities such as type 1 diabetes or chronic hypertension. Datasets were excluded if the women withdrew at any point during the study or if the women delivered elsewhere and were lost to follow up. The study was approved by the Institutional Review Boards of The Hospital for Sick Children (Toronto, ON, Canada, REB Number 1000051548), Mount Sinai Hospital (Toronto, ON, Canada, REB Number 15-0279-A), and Johns Hopkins Hospital University (Baltimore, MD, USA, IRB Number 0082717).

\section{Ultrasound Doppler assessment}

Ultrasound examinations were performed on a 4-weekly interval between 14 and 40 weeks of gestation by certified research sonographers using either a Philips iU22 (Philips Healthcare, Andover, MA, USA) or GE Voluson e10 (GE Healthcare, Chicago, IL, USA) ultrasound system. Pulsed Doppler spectra of the left and right proximal uterine arteries were collected at the crossover point of the external iliac artery and main uterine artery [28]. Patients were followed until delivery and pregnancies were classified retrospectively as either normal or complicated. Normal pregnancies were defined as normotensive women who delivered at term with neonatal birth weight appropriate for gestational age. Complicated pregnancies were defined as one or more of maternal preeclampsia (diagnosed according to ACOG guidelines [29]), preterm birth (delivery < 37 weeks' gestation), or small for gestational age (SGA) neonate (birth weight $<10$ th centile according to population growth charts [30]). The PI for each uterine artery was computed from the traced average Doppler waveforms as the difference between the peak systolic (PSV) and enddiastolic velocities (EDV), divided by the time-averaged mean velocity $(\mathrm{TAMV})$ over the cardiac cycle $(\mathrm{PI}=(\mathrm{PSV}$ -EDV)/TAMV).

\section{Statistical analysis}

All statistical tests were performed using the $\mathrm{R}$ statistical software package (www.r.project.org). Data are reported as mean \pm standard deviation. The left and right uterine artery PI values were averaged to provide the overall mean PI. To analyze the clinical characteristics, a twoway ANOVA was used for continuous variables to evaluate the effect of group (normal, complicated) and fetal sex (female, male), and a Pearson's chi-squared test was used for categorical variables. The uterine artery PI data was analyzed using a linear mixed effects model with gestational age (in completed weeks), group (normal, complicated), fetal sex (female, male), and race (Asian, Black or African American, White, Other) as the fixed effects and a heteroscedastic random effect where intersubject variation varied linearly with gestational age. To assess if the change in uterine artery PI with gestational age was different between groups and fetal sex, the uterine artery PI was modeled as a linear function of gestational age and the change in uterine artery PI was estimated by the slope. A linear model was chosen based on previous studies of uterine artery PI throughout gestation [31, 32]. A value of $p<0.05$ was taken to be significant.

\section{Results}

Patient characteristics

Figure 1 summarizes the number of participants at each stage of the study. Of the 240 women who 


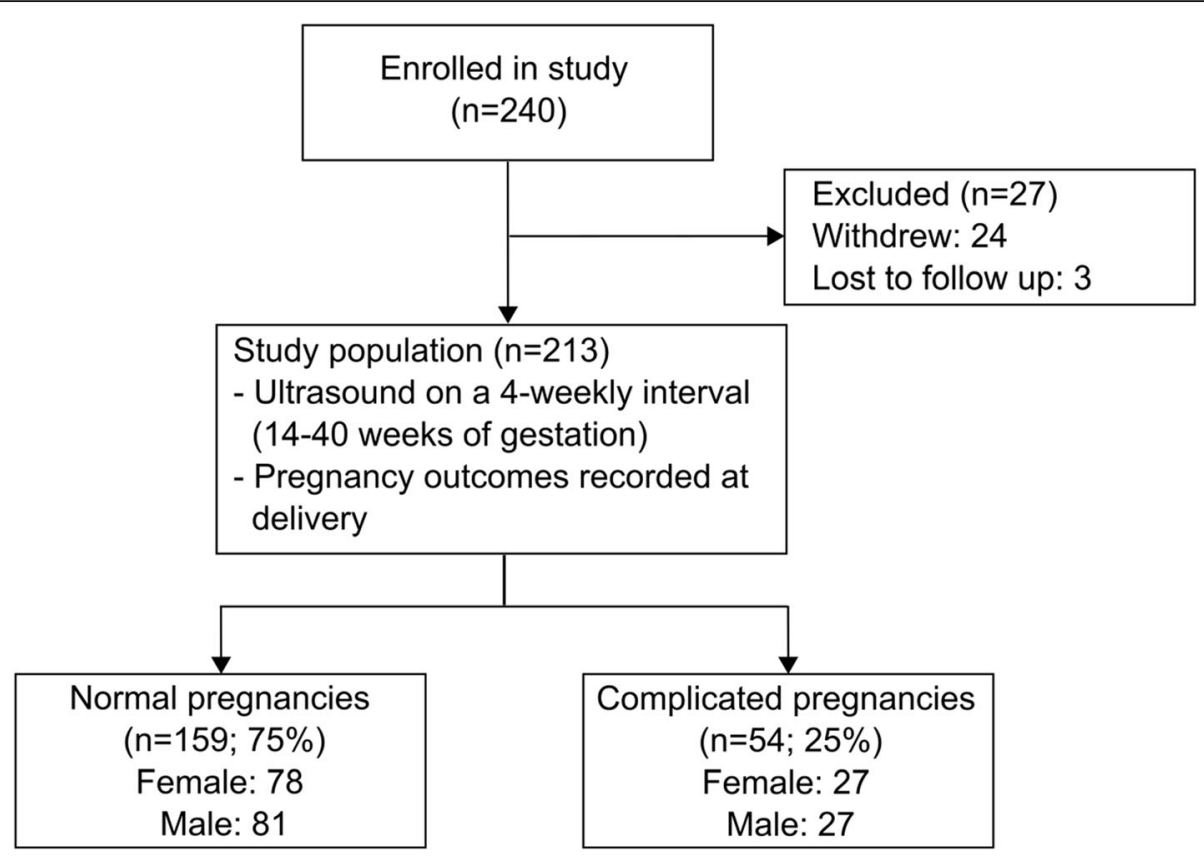

Fig. 1 Diagram of flow of participants through the study. Complicated pregnancy defined as one or more of maternal preeclampsia, preterm birth, or small for gestational age

consented to participate in the study, 213 women underwent ultrasound examinations throughout gestation (24 withdrew and 3 delivered at another site and were lost to follow up). The 213 participants provided a total of 1140 uterine artery measurements (average of 5 per participant). One hundred and fifty-nine of the 213 women $(75 \%)$ met the criteria for the normal pregnancy group (78 female and 81 male infants) and 54 (25\%) met the criteria for the complicated pregnancy group (27 female and 27 male infants). The clinical characteristics of these participants are summarized in Table 1. The birth weights in complicated pregnancies were significantly lower than the normal group $(p<0.0001)$, while male infants weighed more than females in both groups $(p<0.001)$. In complicated pregnancies, there was no significant effect of fetal sex on the incidence of preeclampsia $(22 \%$ females and $30 \%$ males), preterm birth ( $48 \%$ females and $56 \%$ males), or SGA (44\% females and $44 \%$ males).

Table 1 Comparison of maternal demographics and pregnancy and neonatal outcomes

\begin{tabular}{|c|c|c|c|c|}
\hline \multirow[t]{2}{*}{ Characteristic } & \multicolumn{2}{|c|}{ Normal Pregnancy } & \multicolumn{2}{|c|}{ Complicated Pregnancy } \\
\hline & Female $(n=78)$ & Male $(n=81)$ & Female $(n=27)$ & Male $(n=27)$ \\
\hline Maternal age at delivery (years) & $35 \pm 4$ & $34 \pm 4$ & $33 \pm 3$ & $35 \pm 4$ \\
\hline Pre-pregnancy BMI (kg/m²) & $25 \pm 5$ & $25 \pm 5$ & $26 \pm 6$ & $27 \pm 7$ \\
\hline \multicolumn{5}{|l|}{ Race (\%) } \\
\hline Asian & $25(20 / 78)$ & $19(15 / 81)$ & $26(7 / 27)$ & $30(8 / 27)$ \\
\hline Black or African American & $8(6 / 78)$ & $12(10 / 81)$ & $22(6 / 27)$ & $22(6 / 27)$ \\
\hline White & $63(49 / 78)$ & $58(47 / 81)$ & $45(12 / 27)$ & $45(12 / 27)$ \\
\hline Other & $4(3 / 78)$ & $11(9 / 81)$ & $7(2 / 27)$ & $3(1 / 27)$ \\
\hline Cesarean delivery (\%) & $35(27 / 78)$ & $40(32 / 81)$ & $44(12 / 27)$ & $56(15 / 27)$ \\
\hline Gestational age at delivery (weeks) & $38 \pm 1$ & $39 \pm 1$ & $37 \pm 2^{\mathrm{a}}$ & $36 \pm 3^{\mathrm{a}}$ \\
\hline Birth weight (g) & $3200 \pm 400$ & $3500 \pm 500^{b}$ & $2500 \pm 700^{\mathrm{a}}$ & $2600 \pm 700^{a, b}$ \\
\hline
\end{tabular}

${ }^{a} p<0.05$ when compared to normal pregnancy

${ }^{\mathrm{b}} p<0.05$ when compared to females

Data are mean \pm standard deviation or $\%(n / N)$

$B M I$ body mass index; SGA small for gestational age 

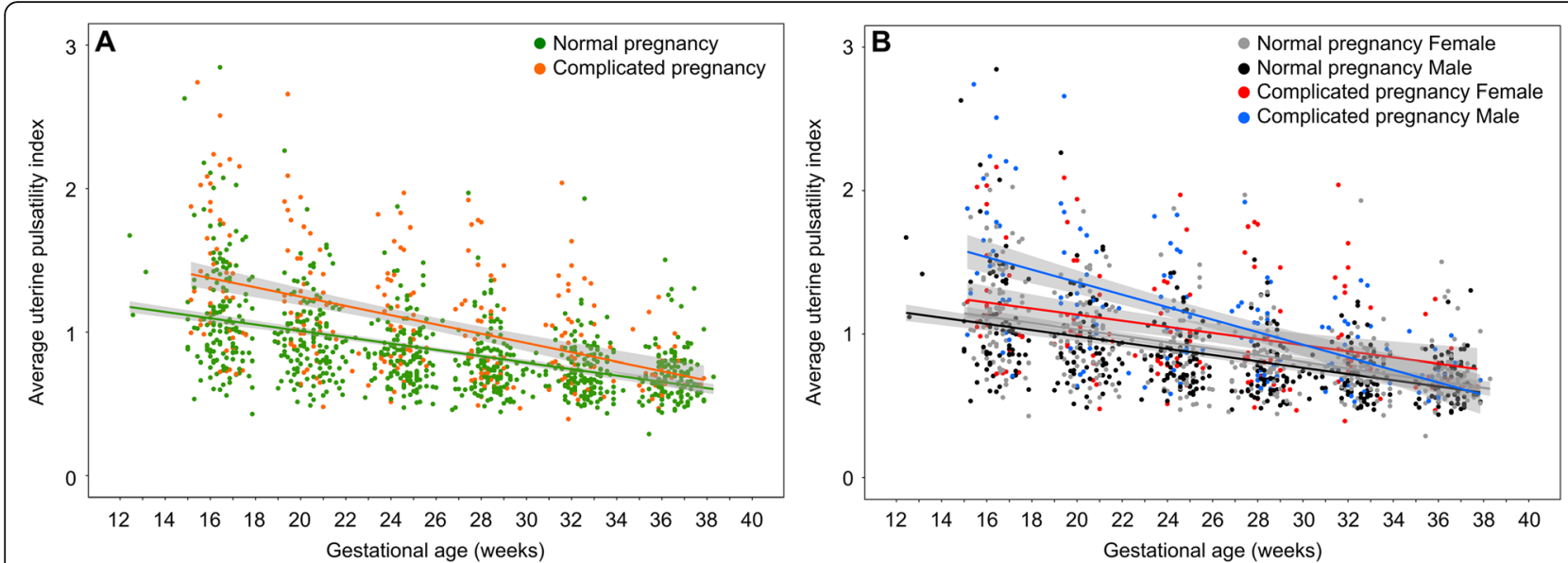

Fig. 2 Average uterine artery pulsatility index over gestation. a Between the normal (green) and complicated pregnancies (orange), there were significant differences in the uterine artery pulsatility index $(p<0.0001)$ and in the rate of change in the uterine artery pulsatility index with gestation ( $p=0.0003)$. b Between the normal (gray: female, black: male) and complicated pregnancies (red: female, blue: male), there were significant gestational age-related sex differences $(p<0.0001)$. The change in uterine artery pulsatility index over gestation was estimated by the slope of the regression. The male complicated pregnancy group had a higher slope of the line $(-0.044 \pm 0.005)$ compared to the other groups (complicated pregnancy female: $-0.021 \pm 0.005$, normal pregnancy male: $-0.022 \pm 0.002$, normal pregnancy female: $-0.023 \pm 0.002)(p<0.0001$ ) The shaded gray areas represent $95 \%$ confidence intervals

\section{Uterine artery PI differed between normal and complicated pregnancies}

Figure 2a shows the change in average uterine artery PI over gestation for normal and complicated pregnancies. As expected, the uterine artery PI decreased with gestational age $(p<0.0001)$ and was significantly elevated in the complicated pregnancies compared to the normal pregnancies $(p<0.0001)$. The rate of change in the uterine artery PI with gestation was significantly different between the normal and complicated pregnancies $(p=$ 0.0003). There was no effect of race on the uterine artery PI or the trajectory of the uterine artery PI with gestation.

\section{Trajectory of uterine artery PI differed by fetal sex for complicated pregnancies}

Figure $2 \mathrm{~b}$ shows the change in average uterine artery PI over gestation for the four study groups. The difference in the rate of change in the uterine artery PI with gestation between the normal and complicated pregnancies depended on fetal sex $(p<0.0001)$. Uterine artery PI change with gestational age was estimated by the intercept and slope of the regression. The male fetuses in the complicated pregnancy group had an elevated slope compared to the other groups $(p<0.0001)$, indicating a significantly greater change in uterine artery PI over gestation. Earlier in gestation $(<28$ weeks), the uterine artery PI for male fetuses in complicated pregnancies was higher than in normal pregnancy. By term, the uterine artery PI for males in complicated pregnancies had returned to normal values. In contrast, the uterine artery PI for females in complicated pregnancies was elevated compared to normal pregnancies throughout gestation and, unlike the male complicated pregnancies, remains elevated at term.

\section{Discussion}

In the present study, the uterine artery PI did not differ over gestation between females and males for normal healthy pregnancies, while it was dependent on fetal sex for pregnancies complicated by either preeclampsia, preterm birth, or fetal growth restriction. Our result in normal pregnancies is consistent with previous studies that reported no sex differences in uterine artery PI at 22-24 weeks' gestation [26] and 31-37 week's gestation [33]. A recent study by Broere-Brown et al. [32] found higher uterine artery PI (reported as a gestational-age-adjusted Z-score) in male fetuses from normal pregnancies in both the second and third trimesters. They also studied pregnancies complicated by preeclampsia, preterm birth, and fetal growth restriction and found the same trend, with males having higher uterine artery PI. Compared to the present study where we did not observe sex differences in normal pregnancies, the difference might be explained by the fact that while the Broere-Brown study had a larger number of participants $(n=4574)$, they only collected measurements at two-time points (once at 1822 weeks' gestation and once at 28-32 weeks' gestation). Our study had a smaller sample size $(n=213)$; however, we obtained on average five measurements per participant, allowing us to accurately characterize the change in uterine artery PI over gestation.

An elevated uterine artery PI is associated with an increased impedance to flow in the uteroplacental 
circulation. In complicated pregnancies, females and males may have contrasting underlying placental pathologies, which deteriorate differentially, and are reflected in the difference in uterine artery PI values over gestation in abnormal pregnancy. Abnormal uterine artery blood flow early in gestation, consistent with the higher uterine artery PI values observed in complicated male pregnancies in this study, may partially explain the higher rates of stillbirth and the increased risk for preterm birth in male fetuses [10, 11, 34, 35]. The significantly higher rate of change in the uterine artery PI with gestation in males is in line with evidence that male fetuses grow faster than females, necessitating more significant maternal adaptations to increase blood flow to the placental circulation [36]. The lower uterine artery PI found here in females in the second trimester relative to males, could protect the pregnancy from early-onset complications. One adverse pregnancy outcome associated with female fetuses is a higher incidence of earlyonset preeclampsia ( $<34$ weeks' gestation) [16-18]. The uterine artery PI is typically measured during the first trimester and is found to be predictive of early-onset preeclampsia, with a lower success at identifying lateonset preeclampsia [37]. However, recent data has shown that assessment of impedance in the uteroplacental circulation by measuring the uterine artery PI during the third trimester has improved screening efficiency for late-onset preeclampsia [31, 38].

A limitation of the current study is that the sample size was underpowered to detect known sex differences in pregnancy outcomes (e.g., incidence of preeclampsia, mortality during gestation, and early neonatal death). Therefore, we were unable to investigate associations between sex-specific pregnancy complications and uterine artery PI. In addition, a larger sample size would allow us to separate the groups into different complications associated with impaired uteroplacental blood flow (e.g., preeclampsia vs. preterm birth). Another limitation of this study is that we were not able to capture uterine artery measurements during the first trimester.

\section{Perspectives and significance}

The principal finding of this work is that changes in uterine artery PI over gestation in complicated pregnancies are dependent on fetal sex. This finding adds to the growing body of known sex differences in fetal and placental development. The uterine artery PI is widely used to assess uteroplacental function in clinical settings. Future investigations are needed to understand the underlying mechanisms for these sex differences in uteroplacental hemodynamics and if sex-specific reference ranges for uterine artery PI could improve pregnancy outcomes.

\section{Acknowledgements}

The authors thank the women who participated in the study.

Authors' contributions

ARC, NM, SS, CLW, and SRH performed the experiments; MW, SS, CLW, SRH, $A A B, J G S, J C K$, and LSC interpreted results of the experiments; LP and LSC analyzed the data and drafted the manuscript; LS, WTP, AAB, CKM, JGS, JCK, and LSC conceived and designed the research; all authors read and

approved the final version of the manuscript.

\section{Funding}

Funding for this work was provided by the Eunice Kennedy Shriver National Institute of Child Health and Human Development of Health Grant U01-

087177-01 and the Banting Research Foundation.

\section{Availability of data and materials}

The datasets used and/or analyzed during the current study are available from the corresponding author on reasonable request.

\section{Ethics approval and consent to participate}

The study was approved by the Institutional Review Boards of The Hospital for Sick Children (Toronto, ON, Canada, REB Number 1000051548), Mount Sinai Hospital (Toronto, ON, Canada, REB Number 15-0279-A), and Johns Hopkins Hospital University (Baltimore, MD, USA, IRB Number 0082717). All participants provided written informed consent to participate in the study.

Consent for publication

Not applicable.

Competing interests

The authors declare that they have no competing interests.

\section{Author details}

${ }^{1}$ Department of Chemistry, Memorial University of Newfoundland, 283 Prince Philip Drive, St John's, Newfoundland and Labrador A1B 3X7, Canada.

${ }^{2}$ Mount Sinai Hospital, Toronto, Ontario, Canada. ${ }^{3}$ Department of Obstetrics and Gynecology, University of Toronto, Toronto, Ontario, Canada. ${ }^{4}$ Division of Cardiology, Department of Paediatrics, The Hospital for Sick Children,

Toronto, Ontario, Canada. ${ }^{5}$ Pregnancy Research Centre, Department of Obstetrics and Gynaecology, Royal Women's Hospital, Parkville, Australia. ${ }^{6}$ Toronto General Hospital Research Institute, University Health Network, Toronto, Ontario, Canada. ${ }^{7}$ Department of Immunology and Institute of Medical Sciences, University of Toronto, Toronto, Ontario, Canada. ${ }^{8}$ Women's College Research Institute, Women's College Hospital, Toronto, Ontario, Canada. ${ }^{9}$ Department of Pathology, Mount Sinai Hospital, Toronto, Ontario, Canada. ${ }^{10}$ Department of Laboratory Medicine and Pathobiology, University of Toronto, Toronto, Ontario, Canada. ${ }^{11}$ Centre for Fetal Therapy, Johns Hopkins Medicine, Baltimore, Maryland, USA. ${ }^{12}$ Translational Medicine, The Hospital for Sick Children, Toronto, Ontario, Canada. ${ }^{13}$ Department of Medical Biophysics, University of Toronto, Toronto, Ontario, Canada. ${ }^{14}$ Mouse Imaging Centre, The Hospital for Sick Children, Toronto, Ontario, Canada.

Received: 18 December 2020 Accepted: 20 January 2021

Published online: 02 February 2021

\section{References}

1. Dixon HG, Robertson WB. A study of the vessels of the placental bed in normotensive and hypertensive women. J Obstet Gynaecol Br Emp. 1958; 65:803-9.

2. Kim YM, Bujold E, Chaiworapongsa T, Gomez R, Hyun Yoon B, Thaler HT, Rotmensch S, Romero R. Failure of physiologic transformation of the spiral arteries in patients with preterm labor and intact membranes. Am J Obstet Gynecol. 2003;189:1063-9.

3. Brosens I, Pijnenborg R, Vercruysse L, Romero R. The "Great Obstetrical Syndromes" are associated with disorders of deep placentation. Am J Obstet Gynecol. 2011;204:193-201.

4. Gómez O, Figueras F, Fernández S, Bennasar M, Martínez JM, Puerto B, Gratacós E. Reference ranges for uterine artery mean pulsatility index at 1141 weeks of gestation. Ultrasound Obstet Gynecol. 2008;32:128-32. 
5. Flo K, Wilsgaard T, Acharya G. A new non-invasive method for measuring uterine vascular resistance and its relationship to uterine artery Doppler indices: a longitudinal study. Ultrasound Obstet Gynecol. 2011;37:538-42.

6. Harrington K, Cooper D, Lees C, Hecher K, Campbell S. Doppler ultrasound of the uterine arteries: the importance of bilateral notching in the prediction of pre-eclampsia, placental abruption or delivery of a small-forgestational-age baby. Ultrasound Obstet Gynecol. 1996;7:182-8.

7. Albaiges G, Missfelder-Lobos H, Lees C, Parra M, Nicolaides KH. One-stage screening for pregnancy complications by colour Doppler assessment of the uterine arteries at 23 weeks' gestation. Obstet Gynecol. 2000;96:559-64.

8. Papageorghiou AT, Yu CK, Bindra R, Pandis G, Nicolaides KH. Multicentre screening for pre-eclampsia and fetal growth restriction by transvaginal uterine artery Doppler at 23 weeks of gestation. Ultrasound Obstet Gynecol. 2001;18:441-9.

9. Valiño N, Giunta G, Gallo DM, Akolekar R, Nicolaides KH. Biophysical and biochemical markers at 30-34 weeks' gestation in the prediction of adverse perinatal outcome. Ultrasound Obstet Gynecol. 2016;47:194-202.

10. Naeye RL, Burt LS, Wright DL, Blanc WA, Tatter D. Neonatal mortality, the male disadvantage. Pediatrics. 1971:48:902-6.

11. Ingemarsson I. Gender aspects of preterm birth. Br J Obstet Gynaecol. 2003; 110:34-8.

12. Di Renzo GC, Rosati A, Sarti RD, Cruciani L, Cutuli AM. Does fetal sex affect pregnancy outcome? Gend Med. 2007:4:19-30.

13. Kent AL, Wright IMR, Abdel-Latif ME. New South Wales and Australian Capital Territory Neonatal Intensive Care Units Audit Group. Mortality and adverse neurologic outcomes are greater in preterm male infants. Pediatrics. 2012;129:124-31.

14. Dunn L, Prior T, Greer R, Kumar S. Gender specific intrapartum and neonatal outcomes for term babies. Eur J Obstet Gynecol Reprod Biol. 2015;185:19-22.

15. Orzack SH, Stubblefield JW, Akmaev VR, Colls P, Munné S, Scholl T, Steinsaltz D, Zuckerman JE. The human sex ratio from conception to birth. Proc Natl Acad Sci USA. 2015;112:E2102-11.

16. Shiozaki A, Matsuda Y, Satoh S, Saito S. Impact of fetal sex in pregnancyinduced hypertension and preeclampsia in Japan. J Reprod Immunol. 2011; 89:133-9.

17. Elsmén E, Källén K, Marsál K, Hellström-Westas L. Fetal gender and gestational-age-related incidence of pre-eclampsia. Acta Obstet Gynecol Scand. 2006:85:1285-91.

18. Taylor BD, Ness RB, Klebanoff MA, Tang G, Roberts JM, Hougaard DM, Skogstrand K, Haggerty CL. The impact of female fetal sex on preeclampsia and the maternal immune milieu. Pregnancy Hypertens. 2018;12:53-7.

19. Sood R, Zehnder JL, Druzin ML, Brown PO. Gene expression patterns in human placenta. Proc Natl Acad Sci USA. 2006;103:5478-83.

20. Clifton VL. Review: sex and the human placenta: mediating differential strategies of fetal growth and survival. Placenta. 2010;31:S33-9.

21. Brown ZA, Schalekamp-Timmermans S, Tiemeier HW, Hofman A, Jaddoe WW, Steegers EAP. Fetal sex specific differences in human placentation: a prospective cohort study. Placenta. 2014;35:359-64.

22. Rosenfeld CS. Sex-specific placental responses in fetal development. Endocrinology. 2015;156:3422-34

23. Andersen LB, Jørgensen JS, Herse F, Andersen MS, Christesen HT, Dechend R. The association between angiogenic markers and fetal sex: implications for preeclampsia research. J Reprod Immunol. 2016;117:24-9.

24. Wallace JM, Bhattacharya S, Horgan GW. Gestational age, gender and parity specific centile charts for placental weight for singleton deliveries in Aberdeen, UK. Placenta. 2013;34:269-74.

25. Walker MG, Fitzgerald B, Keating S, Ray JG, Windrim R, Kingdom JCP. Sexspecific basis of severe placental dysfunction leading to extreme preterm delivery. Placenta. 2012:33:568-71.

26. Widnes C, Flo K, Acharya G. Exploring sexual dimorphism in placental circulation at 22-24 weeks of gestation: a cross-sectional observational study. Placenta. 2017:49:16-22.

27. Widnes C, Flo K, Wilsgaard T, Kiserud T, Acharya G. Sex differences in umbilical artery Doppler indices: a longitudinal study. Biol Sex Differ. 2018;9:16.

28. Bower S, Bewley S, Campbell S. Improved prediction of preeclampsia by two-stage screening of uterine arteries using the early diastolic notch and colour Doppler imaging. Obstet Gynecol. 1993;82:78-83.

29. Executive summary: hypertension in pregnancy, American College of Obstetricians and Gynecologists. Obstet Gynecol. 2013;122:1122-31.

30. Kramer MS, Platt RW, Wen SW, Joseph KS, Allen A, Abrahamowicz M, Blondel B, Bréart G. Fetal/Infant Health Study Group of the Canadian
Perinatal Surveillance System. A new and improved population-based Canadian reference for birth weight for gestational age. Pediatrics. 2001;108: E35.

31. Tayyar A, Guerra L, Wright A, Wright D, Nicolaides KH. Uterine artery pulsatility index in the three trimesters of pregnancy: effects of maternal characteristics and medical history. Ultrasound Obstet Gynecol. 2015;45:68997.

32. Broere-Brown ZA, Schalekamp-Timmermans S, Hofman A, Jaddoe WW, Steegers EAP. Fetal sex dependency of maternal vascular adaptation to pregnancy: a prospective population-based cohort study. Br J Obstet Gynaecol. 2016;123:1087-95.

33. Steier JA, Bergsjø PB, Thorsen T, Myking OL. Human chorionic gonadotropin in maternal serum in relation to fetal gender and utero-placental blood flow. Acta Obstet Gynecol Scand. 2004;83:170-4.

34. Byrne J, Warburton D, Opitz JM, Reynolds JF. Male excess among anatomically normal fetuses in spontaneous abortions. Am J Med Genet. 1987;26:605-11.

35. Vatten LJ, Skjærven R. Offspring sex and pregnancy outcome by length of gestation. Early Hum Dev. 2004;76:47-54.

36. Eriksson JG, Kajantie E, Osmond C, Thornburg K, Barker DJP. Boys live dangerously in the womb. Am J Hum Biol. 2010;22:330-5.

37. O'Gorman N, Wright D, Syngelaki A, Akolekar R, Wright A, Poon LC, Nicolaides $\mathrm{KH}$. Competing risks model in screening for preeclampsia by maternal risk factors and biomarkers at 11-13 weeks gestation. Am J Obstet Gynecol. 2016;213:e1-12.

38. Tsiakkas A, Saiid Y, Wright A, Wright D, Nicolaides KH. Competing risks model in screening for preeclampsia by maternal factors and biomarkers at 30-34 weeks' gestation. Am J Obstet Gynecol. 2016;215:e1-17.

\section{Publisher's Note}

Springer Nature remains neutral with regard to jurisdictional claims in published maps and institutional affiliations.

Ready to submit your research? Choose BMC and benefit from:

- fast, convenient online submission

- thorough peer review by experienced researchers in your field

- rapid publication on acceptance

- support for research data, including large and complex data types

- gold Open Access which fosters wider collaboration and increased citations

- maximum visibility for your research: over $100 \mathrm{M}$ website views per year

At $\mathrm{BMC}$, research is always in progress.

Learn more biomedcentral.com/submissions 